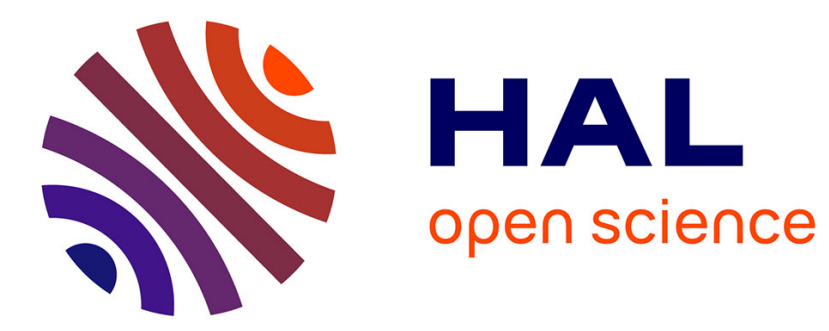

\title{
Prosodic realizations of information focus in French
}

Claire Beyssade, Barbara Hemforth, Jean-Marie Marandin, Cristel Portes

\section{To cite this version:}

Claire Beyssade, Barbara Hemforth, Jean-Marie Marandin, Cristel Portes. Prosodic realizations of information focus in French. Explicit and implicit prosody in sentence processing: Studies in Honor of Janet Dean Fodor, Studies in Theoretical Psycholinguistics (46), Springer, pp.39-62, 2015. halshs01428348

\section{HAL Id: halshs-01428348 https://shs.hal.science/halshs-01428348}

Submitted on 16 Apr 2019

HAL is a multi-disciplinary open access archive for the deposit and dissemination of scientific research documents, whether they are published or not. The documents may come from teaching and research institutions in France or abroad, or from public or private research centers.
L'archive ouverte pluridisciplinaire HAL, est destinée au dépôt et à la diffusion de documents scientifiques de niveau recherche, publiés ou non, émanant des établissements d'enseignement et de recherche français ou étrangers, des laboratoires publics ou privés. 


\title{
Prosodic Realizations of Information Focus in French
}

\author{
Claire Beyssade, Barbara Hemforth, Jean-Marie Marandin \\ and Cristel Portes
}

\begin{abstract}
In this chapter, we provide empirical evidence on the prosodic marking of information focus (IF) in French. We report results from an elicitation experiment and two perception experiments. Based on these experiments, we propose that phrases that resolve a question are set off by two types of intonational markers in French: they host the nuclear pitch accent (NPA) on their right edge and/or they are intonationally highlighted by an initial rise (IR). These intonational markers are very often realized conjointly but can also be applied separately thus leading to considerable variation in our elicitation data. We will propose that some of the variation can be explained by differences in the function of NPA and IR: NPA placement is sensitive to the informational/illocutionary partitioning of the content of utterances, while IRs are sensitive to different types of semantic or pragmatic salience. We also suggest that "question/answer" pairs provide a criterion to identify the IF only if the answer is congruent. Answers may, however, contribute to implicit questions resulting in different prosodic realizations.
\end{abstract}

Keywords Information focus · French - Initial rise

This chapter is a largely extended version of a conference proceedings paper by Beyssade et al 2009. Authors appear in alphabetical order.

C. Beyssade $(\bowtie)$

Institut Jean Nicod, CNRS-ENS-EHESS, 29, rue d'Ulm, 75005 Paris, France

e-mail: claire.beyssade@ens.fr

B. Hemforth · J.-M. Marandin

Laboratoire de Linguistique Formelle (LLF), CNRS-Université Paris Diderot, Place Paul

Ricoeur, 75013 Paris, France

e-mail: barbara.hemforth@linguist.univ-paris-diderot.fr

J.-M. Marandin

e-mail: marandin@linguist.univ-paris-diderot.fr

C. Portes

Laboratoire Parole et Langage (LPL), CNRS-Aix-Marseille Université, 5 avenue Pasteur, 13100

Aix-en-Provence, Francer

e-mail: cristel.portes@lpl-aix.fr

(C) Springer International Publishing Switzerland 2015

L. Frazier, E. Gibson (eds.), Explicit and Implicit Prosody in Sentence Processing,

Studies in Theoretical Psycholinguistics 46, DOI 10.1007/978-3-319-12961-7_3 


\section{Introduction}

The organization of information in a sentence is a central issue in the sentence processing literature as much as in theoretical linguistics. Focusing an element of the current utterance by syntactic or prosodic means contributes to what is perceived as the implicit or explicit question under discussion. The focused element has a high chance of being picked up as the topic of the discourse unit that follows (Dahan et al. 2002). The role of information structure has been studied extensively for phenomena such as clefting, left- or right-dislocation and other syntactic constructions (Colonna et al. 2012; 2014; Drenhaus et al. 2011; de la Fuente and Hemforth 2013). More recently, syntactic realizations of topic and focus are more and more studied in interaction with prosodic realizations using systematic empirical methods (e.g., Repp and Drenhaus in press; Carlson, this volume). A common outcome of these studies is a surprising variability in the way that intonational features such as nuclear pitch accent (NPA) are used across apparently parallel linguistic contexts, but also a variability of choices within individual speakers, and most clearly across languages (Zimmermann and Onea 2011). Only a few languages, however, have been studied in enough detail so far. For most languages intonational means for focus marking are largely understudied from an empirical perspective. Crosslinguistic evidence is, however, indispensible if we want to know which aspects of focus marking are generalizable across languages and which are language specific.

This chapter takes up this issue by investigating the distribution of two intonational markers in French, initial rises (IRs) on the left of focused XPs and NPAs on their right edge. IRs usually take the shape of an $\mathrm{H}$ tone on the left but not necessarily on the first syllable of the XP, while NPAs can take a variety of shapes (we will suggest $\mathrm{H}^{*}, \mathrm{~L}^{*}, \mathrm{H}+\mathrm{L}^{*}$, and $\mathrm{H}^{*}+\mathrm{L}$ as possible NPAs). In a question-answer pair like (1), a typical prosodic realization in French includes a pitch rise on the first syllable of Bernadette (the IR, marked by small capitals here) as well as a variant of an NPA on the last syllable (marked by capitals). As we will spell out in more detail in Sect. 2.2, these two accent types are rather different and we will suggest in Sect. 5 that they serve rather different purposes.

(1) A: Qui est-ce que tu as rencontré hier soir?

Who did you meet last night?

B: J'ai rencontré BERnarDETTE hier soir. I met BernarDETTE last night.

The use of these markers will be investigated in a staged reading aloud experiment. Our results will show that, beyond considerable variation, IRs and NPAs have a tendency to occur jointly in marking the content resolving a wh-question such as Who wrote the famous paper on implicit prosody in 2002? (as opposed to the broad question What happened in psycholinguistics in 2002?). In two perception studies, we will, however, show that they contribute separately to the marking of an XP as the information focus (IF) of the sentence, i.e., as the answer to a wh-question. 
The paper proceeds as follows. We briefly establish our terminology in Sect. 2. In Sect. 3, we describe the corpus obtained via a production experiment and present an analysis assuming the working hypothesis that resolving XPs are information foci. In Sect. 4, we report the results of two perceptual experiments designed to find out whether speakers recognize the two distinct marking strategies observed in the production corpus and relate them to the resolution of questions. In Sect. 5, we present a more comprehensive analysis, which accounts for both intonational marking strategies.

\section{Descriptive Framework}

\subsection{Information Focus}

There is general agreement that, beyond all sorts of more detailed variations, IF in the answer to a wh-question in English can be realized roughly as exemplified in the short question-answer pairs in (2) and (3). For these examples as well as for the rest of the chapter, we take IF to be the XP that resolves a question. In question-answer pairs with speakers A and B as in (2) and (3), the XP resolving the question (Bill in 2 , Sue in 3) are generally marked by an NPA. Placing the NPA on an XP different from the one resolving the question strongly reduces the felicity of the answer.
A: Who did Paul introduce to Sue?
B: a. Paul introduced BILL to Sue
b. \# Paul introduced Bill to SUE
B: a. Paul introduced Bill to SUE
b. \# Paul introduced BILL to Sue

(3) A: Who did Paul introduce Bill to?

There is, however, much less consensus about the phonology of IF in French. Assuming that the full sentence is the answer to the broad question in (4) and that Marie is the answer to the wh-question in (5), there is broad consensus that these two answers are prosodically different, but much less so with respect to the nature of this difference.

Broad question:

$\begin{array}{ll}\text { A) } & \begin{array}{l}\text { Qu'est-ce qui s'est passé? } \\ \text { What happened? }\end{array} \\ \text { B: } \quad \begin{array}{l}\text { Marie est venue }]_{\mathrm{F}} \\ \text { Marie came }\end{array}\end{array}$

Wh-question:

(5)

$\begin{array}{ll}\text { A: } & \text { Qui est venu? } \\ & \text { Who came? } \\ \text { B: } \quad[\text { Marie }]_{\mathrm{F}} \text { est venue. }\end{array}$


At first glance, the phenomenology of the prosodic/intonational realization of resolving XPs in answers is actually varied. As stated by Jun and Fougeron (2002) as well as Fonagy et al. (1979), some aspects of prosodic marking are optional and seem more probabilistic in nature. This variation can be partly, but not fully explained by structural parameters. The segmental structure and the length of the accentual (or phonological) phrase yield different surface realizations of an underlying prosodic structure as well as rhythmic constraints such as constraints on stress clashes. IRs can, for example, be found on the second instead of the first syllable when the first one is a function word (le MAUvais garÇON ment à sa mère, the bad boy lies to his mother, Jun and Fougeron 2000) or not at all when the prosodic unit (the accentual phrase (AP)) is only one or two syllables long (Non, MaRIE est arrivée. No, Mary has arrived.) (see Sect. 2.2 for details on the segmental structure assumed for French). In this chapter, we will discuss the question of how far beyond these structural parameters, parts of the systematicity in the prosodic variation is related to IF in French. Jun and Fougeron (2002) admit that part of the variation may be due to meaning (e.g., semantic importance) and information structure (e.g., contrastive focus). We will claim that at least some of the diversity can be explained by the interplay of the two distinct marking strategies introduced before: the placement of the NPA in the utterance and the intonational highlighting (IR) on the left of phrases. We will, moreover, suggest that these two strategies may be variants related to the semantic/pragmatic status of IF, differentiating the status of being specifically asserted and that of being salient in the content conveyed in the assertion.

In the rest of this chapter, we will report the results of three experiments that contribute evidence relevant to the choice between the competing descriptive or analytical claims currently debated. We assume that the question/answer pair yields a criterion to identify the IF in utterances: the IF is the part of the content of answers that resolves the question. We put this definition to use in the design of several experiments whose results are presented here.

\subsection{Terminology for the Question/Answer Pair}

Let's consider the two dialogues (6a) and (6b), involving discourse participants A and B. As before, we call the question in (6a) a broad question and that in (6b) a wh-question.

(6) a. A: What happened? B: [Jean invited Marie to the party last night. $]_{\mathrm{F}}$ b. A: Who did Jean invite? B: Jean invited [Marie $]_{\mathrm{F}}$ to the party last night.

In (6a), the resolving XP (R-XPs for short henceforth) is the whole sentence; in (6b), it is the Object NP. Under the assumption that IF is the part of content that resolves the question, the IF is contributed by the whole sentence in (6a) and by the Object NP in (6b). Answer (6a) is an answer to a broad question and (6b) an answer to a wh-question (a. o. Lambrecht 1994; Vallduví and Engdahl 1996). It must be kept in mind that the equation " $\mathrm{R}-\mathrm{XP}=\mathrm{IF}$ " is only valid in congruent answers; congruent answers are answers that strictly convey a value for the parameter introduced 
in the question (Krifka 2001; Kadmon 2001); i.e., they give a precise answer to the question explicitly asked. This excludes over- or underinformative answers of any type. This limitation will turn out to be important for the comprehensive analysis of the data we will present in Sect. 5.

It is usually assumed in the literature that resolving the question is an appropriate criterion for IF because it is a criterion for the newness of the content it contributes. The notion of new (vs. old) is, however, notoriously vague. Here, we take it that "new" means the content the speaker proposes for updating the part of the Common Ground under discussion. Accordingly, new is closely linked to the working of the assertion in declaratives: what is new is the part of the content that is specifically asserted by the Speaker (Jacobs 1984). We strictly restrict ourselves to the question/answer pair here. We do not consider corrections or denials which bring about contrastive content (as, e.g., in Jun and Fougeron 2000, or Dohen and Loevenbruck 2004). We assume that the intonational correlates of contrast are different from those of IF (Beyssade et al. 2004; Selkirk 2009).

\subsection{Prosodic Framework}

Our analysis borrows some basic ideas from the Aix-en-Provence school (Di Cristo 1999; Rossi 1999) but is couched in the autosegmental-metrical framework (AMT, Post 2000; Jun and Fougeron 2000, 2002). There is consensus that French intonation has at least two levels of phrasing: the AP, also called phonological phrase, and the intonational phrase (IP) (see Example 7 taken from Jun and Fougeron 2000, p. 215, for the partitioning of a sentence into APs). Moreover, several frameworks assume a third level of intermediate phrase (ip); its relevance has been argued by Michelas and D'Imperio (2012) for reasons independent of focus marking.

(7) Le désagréable garçon ment à sa mère. 'The unpleasant boy lies to his mother' $\left\{\mathrm{LHi} \mathrm{LH}^{*}\right\}\{\}$

The AP is structured by two tonal events: an IR LHi and a final rise LH*. The surface realization of these tones, however, varies depending on different factors such as the number of syllables of the AP and the speech rate, giving rise to the following surface patterns: $\mathrm{LHiLH}^{*}, \mathrm{LH}^{*}, \mathrm{LLH}^{*}, \mathrm{LHiH}^{*}$, and LHiL* (Jun and Fougeron 2002). IPs are marked by boundary tones that may be low $\mathrm{L} \%$ or high $\mathrm{H} \%$.

In Jun and Fougeron (2002), the LHiL* pattern surfaces when the $\mathrm{H}^{*}$ cannot be realized due to undershoot. The inventory of possible pitch accents is therefore $\mathrm{H}^{*}$ or $\mathrm{L}^{*}$ in their proposal. In order to account for the tonal phenomenology at the right edge of the AP, we assume two more pitch accents borrowed from Ladd (2008, p. 122). ${ }^{1}$ These are bitonal pitch accents: $\mathrm{H}+\mathrm{L}^{*}$ accounts for patterns where the pitch peak occurs on the penultimate preaccentual syllable, $\mathrm{H}^{*}+\mathrm{L}$ codes for a rising-falling movement on the last accented syllable. Therefore, our inventory of

${ }^{1}$ For further arguments in favor of this coding, see Portes and Beyssade (to appear). 


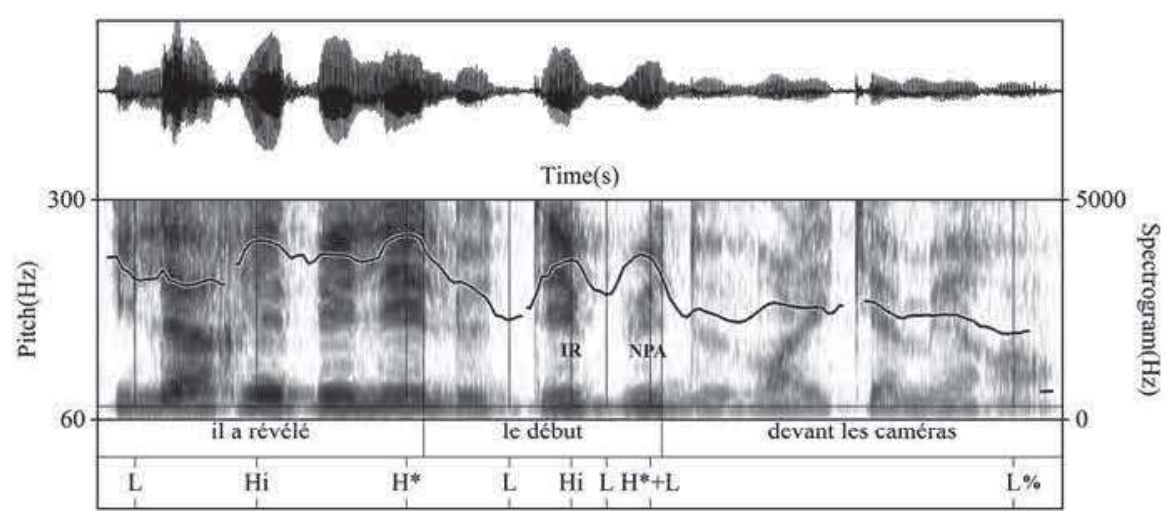

Fig. 1 Answer to a wh-question with the direct object "le début" (the beginning) as the resolving XP in the sentence "il a révélé le début devant les caméras" (he revealed the beginning in front of the cameras)

pitch accent occurring in nuclear position (i.e., as the last pitch accent in the IP) is the following: $\mathrm{H}^{*}, \mathrm{~L}^{*}, \mathrm{H}+\mathrm{L}^{*}$, and $\mathrm{H}^{*}+\mathrm{L}$.

Several authors have observed that narrow information foci or contrastive foci are followed by "deaccented" phrases up to the end of the utterance: they are intonationally realized with high or low constant pitch depending on the height of the previous tonal target. ${ }^{2}$ Here, we model deaccenting through the spreading of the boundary tone, which copies the final tone of the NPA: it is an H\% when the NPA ends with an $\mathrm{H}$ tone $\left(\mathrm{H}^{*}\right)$ and an $\mathrm{L} \%$ when the NPA ends with an $\mathrm{L}$ tone $\left(\mathrm{L}^{*}, \mathrm{H}+\mathrm{L}^{*}\right.$, and $\mathrm{H}^{*}+\mathrm{L}$ ).

Therefore, in case of deaccenting, the NPA $\left(\mathrm{H}^{*}+\mathrm{L}\right.$ in Fig. 1$)$ is moved back to the right edge of the focused phrase while the boundary tone spreads through the deaccented following phrases. The global contour is, thus, preserved as well as its dialogical meaning (Beyssade and Marandin 2007; Portes and Beyssade to appear).

Moreover, several authors have proposed that the optional IR LHi should play a role in the marking of IF. Di Cristo (1999) claims that the IR is more often realized at the left edge of the focused constituent. In this case it may surface with a wider pitch range, giving rise to a specific "accent emphatique" ou "accent de contraste" (emphatic accent or contrastive accent). ${ }^{3}$ German and D'Imperio (2010) also found that LHi is more likely to occur at the left edge of a contrastive focus domain, without mentioning any scaling differences. In this study, we assume the tonal marking of the left edge of the focused constituent under the descriptive label "IR." It has been observed that it may form an "accentual arch" with the following rising accent $\mathrm{LH}^{*}$ (or $\mathrm{LH}+\mathrm{L}^{*}$, or $\mathrm{LH}^{*}+\mathrm{L}$ ), or trigger a high plateau up to the following accent

\footnotetext{
${ }^{2}$ See, however, Féry (2014) for evidence that deaccenting or compression may be restricted to adjuncts. (see Di Cristo \& Jankowski 1999, for an analysis in favor of compression). Since post-focal elements in our study are never arguments, this distinction does not apply here.

${ }^{3}$ Concerning the phonetic realization of the initial rise, we refer the reader to Astésano (2001), which is the most comprehensive and detailed approach to our knowledge.
} 
when the intermediate L tone is not realized. The IR or the high plateau may be implemented quite high in the pitch range.

\subsection{Focus Marking}

Following our brief description of the prosodic framework, we assume Beyssade et al.'s (2004) analysis of IF marking: the phrase contributing the IF hosts the NPA on its right edge. This assumption follows Di Cristo's proposal that the right edge of XPs contributing the IF provides the site for anchoring the nuclear accent. According to Di Cristo, the nuclear accent is a low tone in declarative sentences. Beyssade et al. take up Di Cristo's claim and generalize it: on the basis of corpus observations, they claim that the right edge of focal XPs may anchor the whole repertory of NPAs in French $\left(\mathrm{H}^{*}, \mathrm{~L}^{*}, \mathrm{H}+\mathrm{L}^{*}\right.$, and $\left.\mathrm{H}^{*}+\mathrm{L}\right)$, as the choice of the NPA is independently determined by dialogical parameters. Such a claim directly explains some of the variability of the occurrence of the nuclear contour: as it occurs at the right edge of the phrase contributing the IF, we expect it within the utterance when IF is narrow and the focused XP is non-final and at the end of the utterance when IF is broad. In both approaches, IF marking is identical for IF in wh- and broad questions: in the former case, IF is contributed by a phrase while it is contributed by the whole sentence in the latter. Moreover, Di Cristo and Beyssade et al. also observe that an IR may occur on the left syllable(s) of the phrase conveying narrow IF. Di Cristo proposes that IR marks the left edge of the narrow focal XP: he speaks of bilateral marking of Focus. As for Beyssade et al., they speculate that IR can be related to contrastive focus (following Rossi 1999; see Experiment III for a more detailed discussion of this proposal).

The goal of this chapter is to test the following claim

- IF marking in French resorts to two means: placement of the NPA and IR.

Furthermore, we want to investigate the interplay of these two types of marking. Finally, we address the question of whether this double strategy is functionally equivalent or associated with distinct roles for the discourse.

\section{Production and Comprehension of Prosodically Marked XPs}

\subsection{Experiment I: Elicitation of IF in a Staged Reading Aloud Task}

Our first experiment used staged reading aloud as the experimental paradigm. We thus created a corpus of answers to broad and wh-questions. 


\section{Methods}

Participants Fourteen participants from the University of Paris Descartes volunteered to take part in this study: ${ }^{4}$ ten of them were psychology students who received course credits for participation and four were psychological staff. None of the participants had any training in linguistics. Participants were naïve with respect to our research question.

Materials The corpus of answers we analyze here has been elicited via a production experiment. In the full corpus, we varied not only broad and wh-questions, but also prosodic/intonational realizations of the associate of the adverb seulement (only) (Beyssade et al. 2008). All in all, we created 32 sets of items such as (9) within short contexts such as (8) with eight variants each. The eight variants were distributed across eight lists following a Latin square design. Only two of the conditions directly relating to the question of IF with four items per condition per participant will be discussed in this chapter. In these two conditions, we varied the question type: wh-questions (bearing on the direct Object) (9a) and broad questions (bearing on the whole sentence) (9b). Importantly, all entities in the answer were introduced in the context, including the direct Object, which was introduced as part of a set of alternatives. For wh-questions, the XP following the Object was always introduced in the question thus making it impossible to consider it as part of IF or as additional information related to IF (in the sense of a side structure, Klein and Stutterheim 2002).

Procedure The short texts, involving a description of the context such as (8) were presented to the subjects visually as well as auditorily with one of the two types of questions: a wh-question (bearing on the Object) (9a) or a broad question (bearing on the whole sentence) (9b). The subjects' task was to read aloud answers as if they were actually participating in a dialogue. The participants' answers were recorded in a sound-attenuated room. The 32 target items were pseudorandomly interspersed with 32 fillers, partly from a different experiment on the prosody of coordinations. Four practice items were presented to familiarize participants with the experimental set-up. Out of the $112(8 * 14)$ answers we recorded, we only analyzed 107: Five answers were not taken into account in our quantitative analyses because of disfluencies or production errors.

(8) Context [translated]: Richard is a policeman. He has to treat various documents (videos, leaflets, K7s) seized in a terrorist cache.

(9) a. Le responsable: Qu'as-tu visionné la nuit dernière?

What did you screen last night?

Richard: J'ai visionné les vidéos la nuit dernière.

I screened the videos last night

b. Le responsable: Où en es-tu dans ton enquête?

What's up with your investigation?

Richard: J'ai visionné les vidéos la nuit dernière.

I screened the videos last night

\footnotetext{
${ }^{4}$ We actually recorded four more participants whose data we could not include because they turned out to be bilingual or very disfluent readers.
} 


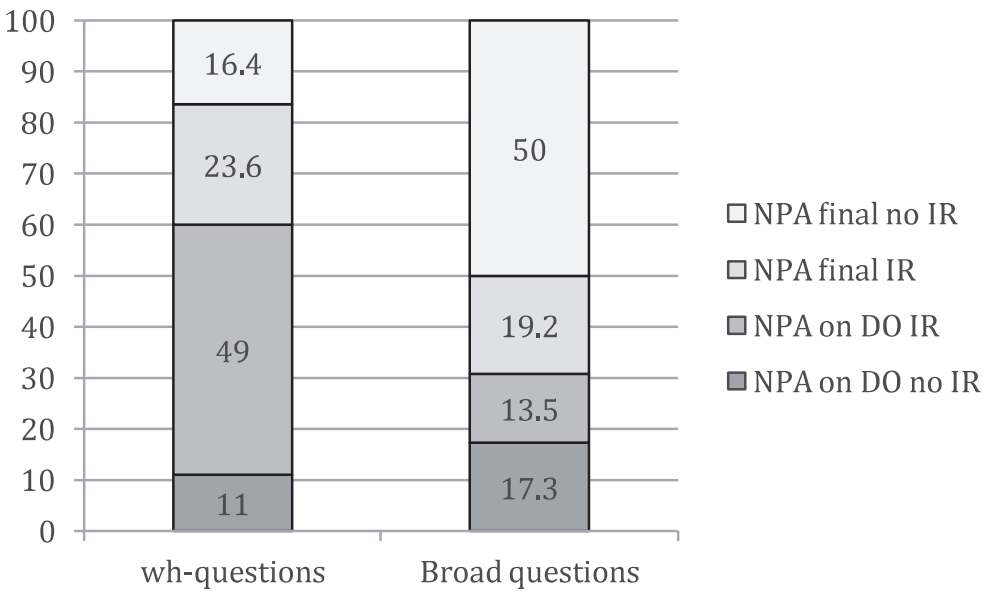

Fig. 2 Prosodic realizations for wh- and broad questions in percent

\subsection{Results}

All answers were coded blindly by the three native French authors without access to the experimental conditions in which they had been produced. In cases of disagreement, the respective answers were discussed in joint meetings until agreement was reached. All answers were coded for IRs on the Object, NPAs on the right edge of the Object, and sentence final NPA. Four different contours were identified: sentence final NPA with IR on the Object, NPA on the right edge of the Object with IR on the left of the Object (not necessarily on the left edge), NPA on the right edge of the Object without IR, and sentence final NPA without IR. We will first look at the general distribution of the different contours for the two question types before presenting NPA and IR distributions separately in more detail. Figure 2 shows the distribution of the different contours for wh- and broad questions. The different contours are obviously not equally distributed (Chisquare $(3)=38,83, p<0.001$ ). While the production of final NPA plus IR on the Object was not significantly different across conditions $(p>0.40)$, NPA on the Object plus IR was clearly much more dominant for wh-questions (Chisquare $(1)=19.44, p<0.001$ ). No significant difference was established for NPA on the Object without IR $(p>0.20)$. Final NPA without IR was, however, significantly more frequent for broad questions (Chisquare $(1)=17.515$, $p<0.001)$.

Looking separately at the occurrence of NPA and IR, we can see that NPA was produced significantly more often sentence finally for broad questions than for whquestions (Chisquare $(1)=7.72, p<0.01$ ), while the inverse was true for NPA on the right edge of the direct object (Chisquare $(1)=9.24, p<0.01)$ (Fig. 3).

IR on the left of the direct object was realized significantly more often for whquestions than for broad questions (Chisquare $(1)=15.01, p<0.001$ ).

Summing up, we can say that the Object noun phrases in answers to wh-questions are distinguished in three different ways: 

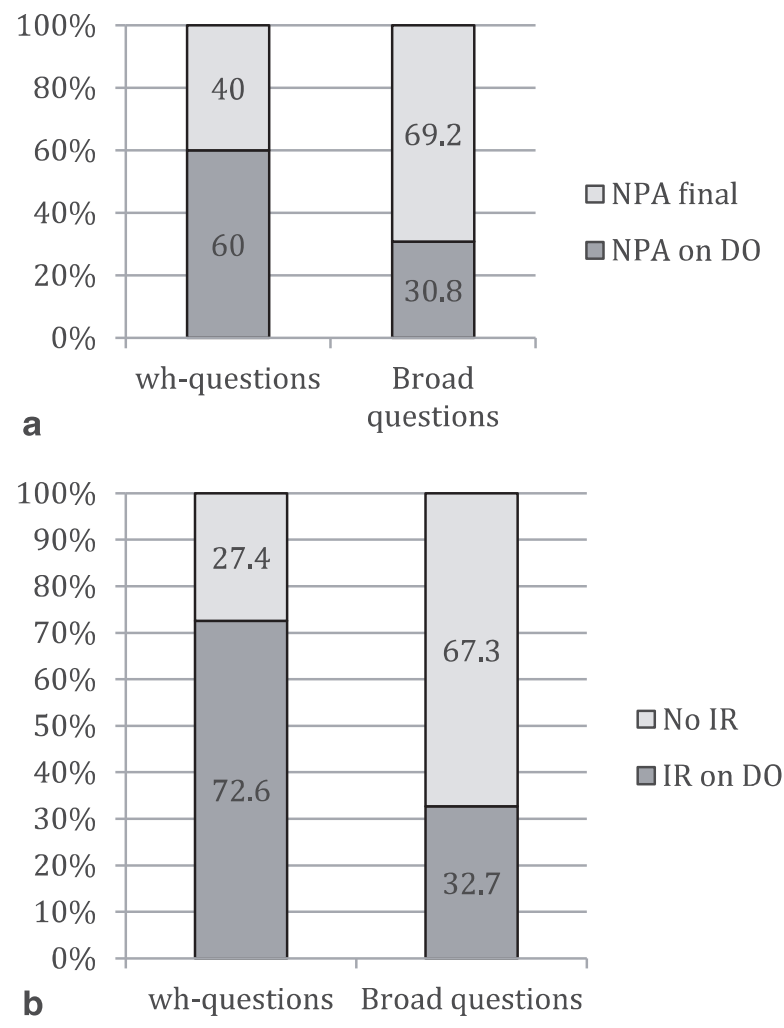

Fig. 3 a Realization of NP for wh- and broad questions. b Realization of initial rise (IR) for whand broad questions

(10) a. The direct Object hosts the NPA on its right edge with an IR (initial rise) on the left (Fig. 4);

b. The direct Object hosts the NPA on its right edge without IR (Fig. 5);

c. The direct Object shows an IR, while the NPA occurs at the end of the utterance (Fig. 6).

Pattern (10a) conjoins the placement of NPA and IR. It is the most frequent pattern with $49 \%$ of all answers. NPA placement and IR appear separately in the two other patterns (10b and 10c). Pattern (10b) features the placement of the NPA on the Object with the corresponding deaccenting of the PP to the right. ${ }^{5}$ It is the least attested pattern (11\% of the all answers). Pattern (10c) highlights the Object, while the NPA occurs at the end of the utterance. Crucially, the PP to the right of the Object is not deaccented. This pattern is well represented in the corpus: $23.6 \%$ of all answers.

\footnotetext{
${ }^{5}$ See, however, Féry (2014) who shows that deaccentuation does not necessarily occur in postfocal regions. It does at least not seem to be obligatory for verbal arguments. Since postfocal elements in our study are never arguments, this distinction does not apply here.
} 


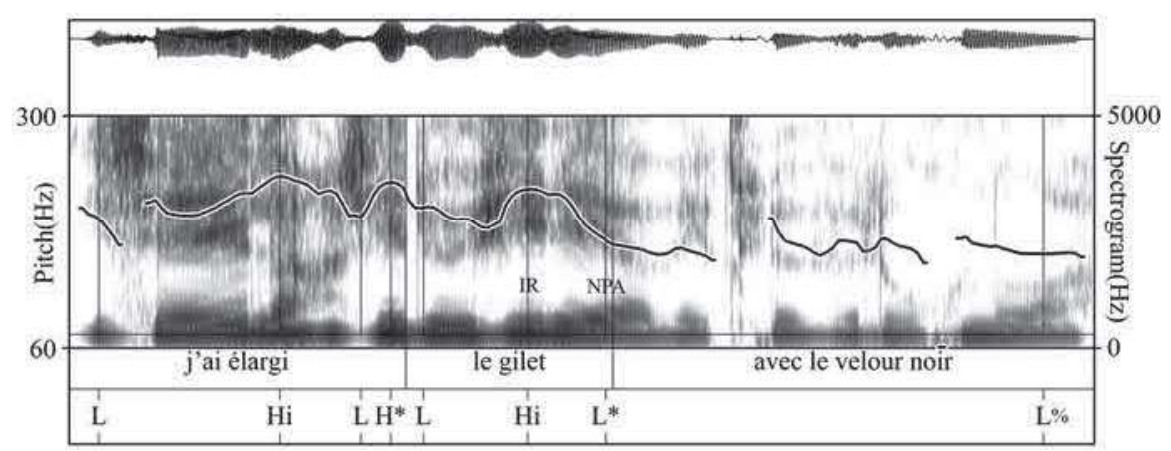

Fig. 4 Answers with pattern 10a: initial rise (IR) on direct Object (with a high implemented initial accent) and Object-final nuclear pitch accent (NPA)

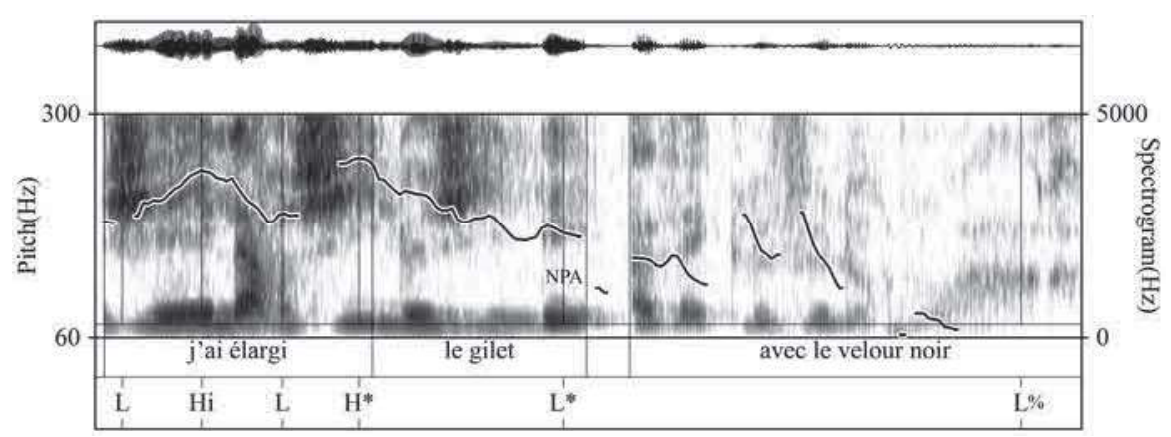

Fig. 5 Answers with pattern 10b: Object-final nuclear pitch accent (NPA) and no initial rise (IR)

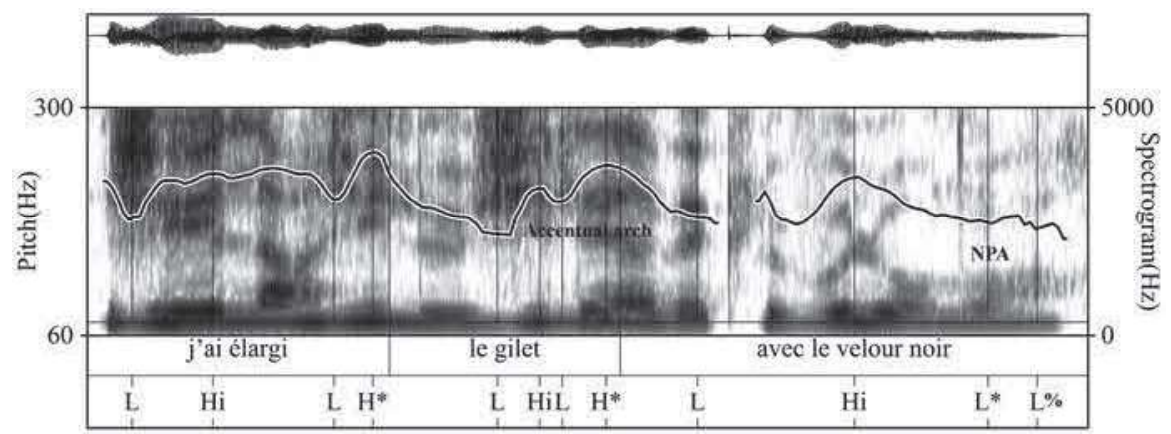

Fig. 6 Answers with initial rise (IR) on the direct object (realization of an accentual arch $\mathrm{Hi}-\mathrm{H}^{*}$ ) and utterance-final nuclear pitch accent (NPA) (10c) 


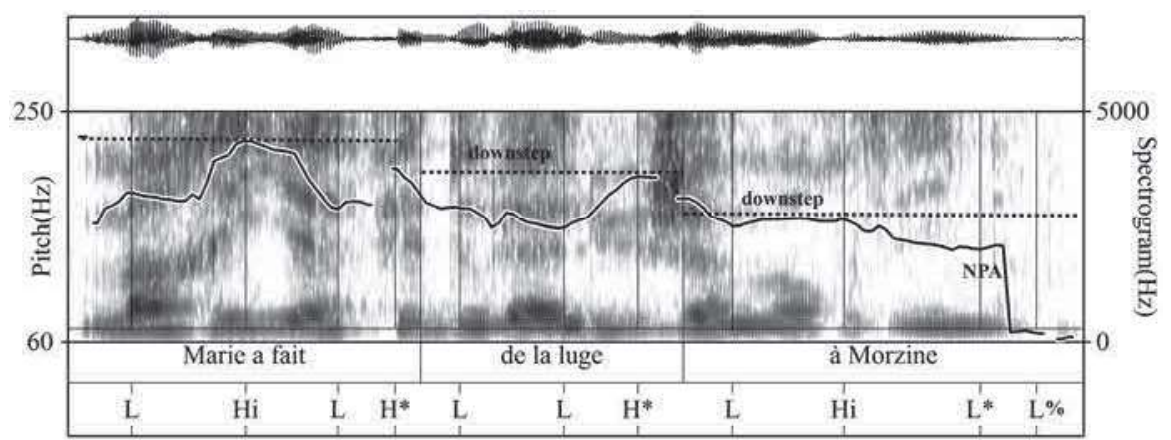

Fig. 7 Answers with utterance-final nuclear pitch accent (NPA) and downstep of the second and third accentual phrases (Aps). Downstep is modeled as a reference base line defined by the $\mathrm{H}$ targets (dashed line in bold) as proposed by van den Berg et al. (1992)

Finally, there are $16.4 \%$ of the answers in which the Object is not set off by any means: we come back to them in Sect. 5 below.

\section{Answers to Broad Questions}

Let's now look at answers to broad questions: $69.2 \%$ of the answers to broad questions show pattern (11):

(11) NPA occurs at the right edge of the utterance (NPA is utterance final).

Pattern (11) mostly gives rise to a regular downstep of the APs following the initial AP (Fig. 7). No constituent is highlighted: no high implemented initial accent (IR) can be seen. This pattern corresponds to $50 \%$ of all answers to broad questions. The remaining answers feature one of the patterns described in (10) for answers to a wh-question. $30.8 \%$ of all answers show the NPA on the right edge of the Object, which corresponds to patterns $(10 \mathrm{a}=$ with IR: $13.5 \%)$ and $(10 \mathrm{~b}=$ without IR: $17.3 \%)$. Moreover, $19.2 \%$ of the answers with the NPA on the right edge of the utterance feature a highlighted Object, which corresponds to pattern (10c). We come back to those two cases in Sect. 5 below.

\section{NPA Contours}

In our corpus, we found several types of NPA contours at the right edge of IF, which corroborates Beyssade et al.'s (2004) generalization. Three types of nuclear pitch movement are attested in the corpus:

1. Falls (corresponding to Di Cristo's B or Beyssade et al.'s L*) (Figs. 4, 5 and 6) above.

2. Falls from the penultimate, which corresponds to Ladd's (2008) $\mathrm{H}+\mathrm{L}^{*}$ : the pitch peak occurs on the penultimate syllable and the following valley on the last syllable. This is illustrated for IF in an answer to a wh-question in Fig. 8. 


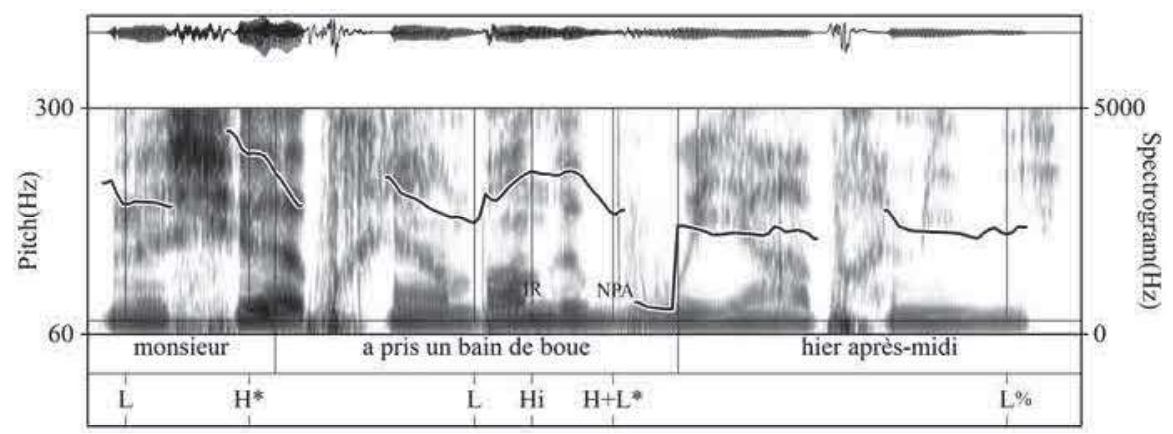

Fig. 8 Answer to a wh-question with a fall from the penultimate $\left(\mathrm{H}+\mathrm{L}^{*}\right)$ nuclear pitch accent (NPA) occurring at the right edge of the focused Object "bain de boue." Note that an initial accent occurs on "bain" immediately followed by the leading tone $\mathrm{H}+$ of the $\mathrm{H}+\mathrm{L} *$ pitch accent on the penultimate syllable "de" which contains a schwa.

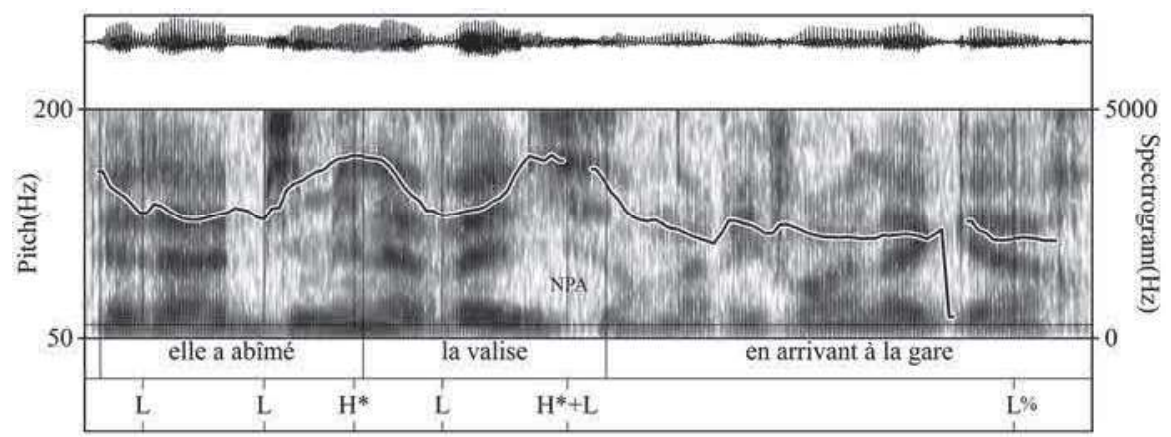

Fig. 9 Answer to a wh-question with a rise-fall $\left(\mathrm{H}^{*}+\mathrm{L}\right)$ nuclear pitch accent (NPA) occurring at the right edge of the focused Object NP "la valise".

3. Rise-falls ( $\mathrm{H}^{*}+\mathrm{L}$ in Ladd 2008 and Portes and Beyssade to appear) for which the pitch peak and the following valley occur on the last syllable as illustrated for IF in answers to wh-questions in Fig. 9.

\subsection{Discussion}

We first analyze the patterns we observed in the data assuming the working hypothesis that the resolving XPs (R-XPs) are IFs and the intonational approach to IF marking as defined in (11) as proposed by Di Cristo (1999) and Beyssade et al. (2004).

(12) XPs contributing the Information Focus host the Nuclear Pitch Accent on their right edge. 
Claim (12) is corroborated in the majority of the cases in our production experiment: $60 \%$ of the answers to a wh-question show the NPA at the right edge of the Object whereas $69.2 \%$ of the answers to a broad question show the NPA on the right edge of the utterance. Three different NPA contours were moreover found in our corpus (falls, falls from the penultimate, and rise-falls) as predicted by Beyssade et al. (2004).

Nevertheless, there are facts that do not fit the picture predicted by (12) and call for another analysis: $72.6 \%$ of the answers to a wh-question show an IR on the object, which is compatible with, but not predicted by (12). Among them, $23.6 \%$ show only the IR on the Object, while the NPA is docked at the right edge of the sentence (corresponding to pattern 10c) for the remaining $49 \%$ the NPA is on the right edge of the direct object (pattern 10a).

We propose the hypothesis in (13) to account for the use of IR in answers:

(13) The XP resolving a narrow question may be marked by NPA placement or by IR.

We devote the next section to the corroboration of (13).

\section{The Role of the IR}

We ran two perception experiments in order to test hypothesis (13). In Experiment II, we are testing whether IRs alone can be recognized as a way of marking the XP resolving a question. In Experiment III, we asked whether IR is linked to the expression of Contrast (as suggested by Rossi 1999 and taken up by Beyssade et al. 2004).

\subsection{Experiment II}

\section{Methods}

Participants The experiment involved 24 participants, native speakers of French, first-year undergrad students in Humanities at U. Paris Diderot. All participants were naïve as to the research questions of our experiments.

Materials and Procedure We selected 20 answers from the preceding corpus, all of them particularly clear examples of the different intonational contours we wanted to examine: ten realizations with NPA at the end of the sentence and no IR that are supposed to be identified as answers to broad questions, ten with marking of the Object (five with NPA and five with IR only) which, conversely, are predicted to be identified as answers to wh-questions. The sentences were presented in two blocks. The first block is composed of five answers with final NPA (hypothesized answers to broad questions) and five sentences with final NPA and IR on the object NP (hypothesized answers to wh-questions). The second block is composed of five answers with final NPA (expected answers to broad questions) and five answers with NPA on the object NP (expected answers to wh-questions). The ten sentences 
Fig. 10 Results of Experiment II. Percentages of whquestion choices associated with each prosodic pattern

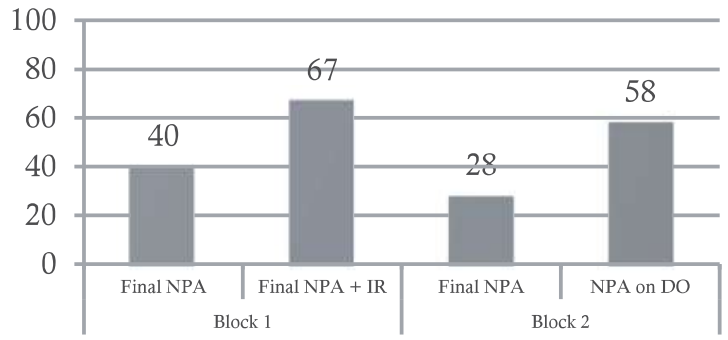

composing each block were presented in random order. The subjects had to listen to the selected items and to judge to which of two visually presented questions the current sentence had been produced as an answer (14). Each session was run in a quiet room within the Paris Diderot library, where we recruited our participants. The sessions lasted at most $15 \mathrm{~min}$, which made recruiting voluntary participants relatively easy. We also kept the experiment short to avoid habituation effects.

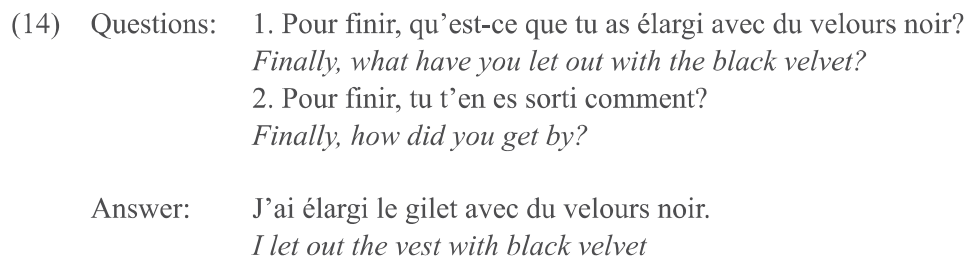

\section{Results}

Figure 10 shows how often participants chose wh-questions as relevant for the heard answer. Participants clearly distinguished answers with Final NPA and answers with highlighted Objects (IR on direct Object (DO)) in block 1, as well as between with NPA at the end (Final NPA) and answers with NPA at the right edge of DO (NPA on DO) in block 2 . They chose the wh-questions reliably more often for answers with IR on DO than for answers with final NPA $(67$ vs. $40 \%$; $\mathrm{F}(1,24)=19.54 ; p<0.001)$. They also chose the wh-question reliably more often for answers with NPA on DO $(58 \%)$ than for answers with final NPA $(28 \%, F 1,24=23.93 ; p<0.001)$. No reliable difference between answers with IR on DO and those with NPA on DO could be established.

\section{Conclusion}

The results of Experiment II corroborate our Hypothesis (13): utterances with NPA on the direct Object or with IR on the direct Object are similarly recognized as answers to wh-questions bearing on the direct Object. However, the data also show 
that the intonational marking does not lead to unambiguous interpretations. Sentence final NPA is still considered as compatible with a wh-question in $34 \%$ of the cases on average ( $40 \%$ in Block 1 and $28 \%$ in Block 2), and IR or NPA on the direct Object is considered as compatible with a broad question in $37.5 \%$ of the cases on average (33\% in Block 1 and $42 \%$ in Block 2). In the following section, we will present data on the role of sets of alternatives for IF in the preceding context.

\subsection{Experiment III}

The presence of IR in our production data concerns $72.6 \%$ of all responses to whquestions. Looking for an explanation, we linked this massive occurrence to the systematic presence of a set of alternatives in all of the eliciting contexts (see, for example, "films, leaflets, K7" in (8) above). We, thus, designed a second perception experiment in order to test the hypothesis that IR is related to the expression of Contrast as formulated by Rossi (1999, see also Beyssade et al. 2004). We define the notion of contrast as a membership relation in a set of alternatives activated in the immediate context (Chafe 1974).

\section{Methods}

The only difference between Experiments II and III is that we added a sentence presenting a set of alternatives in the description of the context before the presentation of the question. Otherwise, the procedure was identical. For example, context (15) in which the phrase "le gilet et la veste" corresponds to a set of two possible choices has been added to (14). If the presence of a set of alternatives plays a central role for the presence of IR, we expect the choice of wh-questions to increase for sentence with IR on the direct Object compared to Experiment II. The experiment involved 17 participants, native speakers of French, first-year undergraduate students in Humanities at U. Paris Diderot, who had not participated in Experiment II. The experiment was run using the same procedure and under the same circumstances as Experiment II.

(15) Pierre ne rentre plus dans son costume: le gilet et la veste sont trop serrés. Comme il est tailleur, il va faire les retouches.

His suit does not fit Pierre any longer: the vest and the jacket are too tight. As he is a tailor, he will alter them.

\section{Results}

Figure 11 shows the percentage of wh-questions chosen by participants to be consistent with the heard answer. The pattern is nearly identical to that of Experiment II. The 17 subjects chose the wh-question reliably more often for answers with 
Fig. 11 Results of Experiment III: percentages of whquestion choices associated with each prosodic pattern

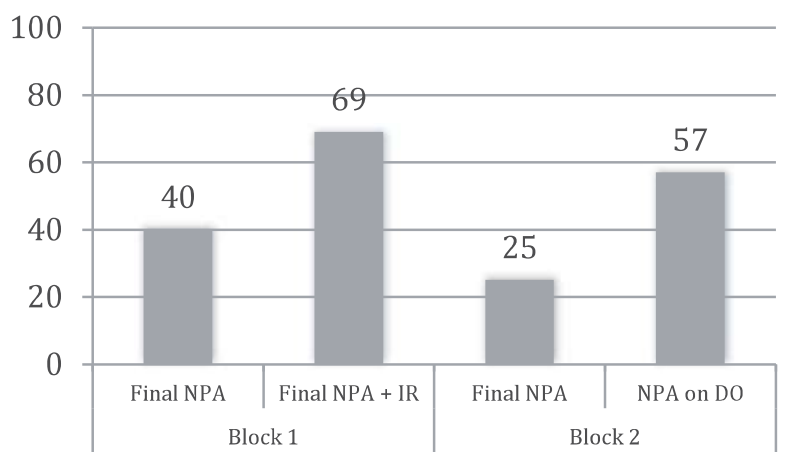

IR on NP $(67 \%)$ than for answers with final NPA (69 vs. $40 \%$; $F(1,17)=8.86$, $p<0.01)$. They also chose the wh-question reliably more often for answers with NPA on NP than for answers with final NPA (57 vs. $25 \%, \mathrm{~F}(1,17)=5.12, p<0.04)$. No reliable difference between answers with IR on NP and those with NPA on NP could be established.

\section{Discussion}

The presence of alternatives in the immediate context does not influence the choice of the question types corresponding to different intonational contours of the R-XPs. The results were actually nearly identical to those of Experiment II.

\subsection{Conclusion of Perception Experiments}

Both experiments show that speakers recognize the highlighting of the Object as a cue to its saliency in the answer as it resolves the question. Accordingly, we conclude that hypothesis (13) is corroborated. Participants did, however, interpret the intonational marking fairly directly and independent of the sets of alternatives provided in the context.

\section{General Discussion}

In our elicitation and perception experiments, we were able to show the variable marking of IF in French. Direct objects serving as answers to wh-questions can be marked by IRs on their left, by NPAs on their right edge or both. IR and NPA on the direct object are independently perceived as cues for IF although they most often occur conjointly. IR can even occur on the direct object in answers to broad questions. This observed variation in the data can of course be just evidence for variation 
with not much more to add. We would, however, like to propose that some of the variation may be explained by the assumption that NPA placement and IR do not necessarily cue the same phenomenon. We will propose that NPA placement is sensitive to the illocutionary import of the content of the utterance, while IR is considered a polyvalent means to give intonational prominence to the content of a phrase.

\subsection{Background: “Congruent" vs. "Noncongruent" Answers}

In Sect. 2.1, we took up the accepted distinction between congruent vs. noncongruent answers. The equation between IF and resolving XP (R-XP) holds only in congruent answers. But, we know that in naturally occurring contexts, dialogue participants quite often answer in a noncongruent way: they contribute underinformative or over-informative answers (Krifka 2001). This is easily explained by reasons of cooperation or default of cooperation. Speakers infer the current question under discussion, which may be the explicit question but can as easily be an implicit underlying question (Ginzburg 1995a, b; Roberts 1996; see also Clifton and Frazier 2012 for processing evidence). For example, it is very common that speakers offer apparently over-informative answers anticipating underlying reason for the question on the part of the questioner. This is the case with over-informative answers in (16) and (17) below: in (16), the speaker does not produce a direct answer to the polar question "Est-ce que quelqu'un t'a contacté?", but she produces an answer to the wh-question "Qui t'a contacté?", and this answer implies that the answer to the polar question is positive. In (17), the answer resolves the question and contributes more precise information about the issue raised by the question.

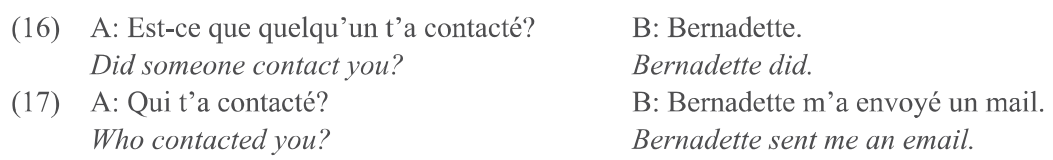

A case of underinformative response is given in (18): the answer does not resolve the question, while it contributes relevant information about the question.

(18) A: Qui t'a contacté?

Who contacted you?

B: II n'y a pas eu d'appel.

There was no call.

To recapitulate, discourse participants - when they answer - do not simply resolve the explicit question of the interlocutor; they have their own agenda and the answers they offer are a trade-off between what is required by the interlocutor's question, what they think is required and which information they are able/willing to give. In experiments, in the lab, one does not control that aspect of the answers all that well, nor do we necessarily do so in natural dialogues. Accordingly, we do expect that not all answers we have elicited are answers to the explicitly asked questions. 


\subsection{Proposal}

Phrases that resolve a question (be they a constituent in a clause or the entire sentence) have a double status: a semantic status in that they resolve the question, but also a pragmatic status in that they contribute the new content, viz., that part of content that makes up the update brought forth by the assertion.

It is currently assumed that those two statuses are interdependent and coincide. They certainly do in congruent answers. Now, part of the working of noncongruent answers can be explained by the fact that they can be dissociated. For example, in (17), Bernadette resolves the question while the whole answer contributes the update brought over by the answer. If the statuses can be teased apart, their cueing possibly can be too. Hence, we propose that:

(19) NPA placement cues the part of the content that contributes to the update brought by the answer.

(20) [Provisory] IR cues the constituent that resolves the question.

We will use the label "pragmatic marking" for (19) and "semantic marking" for (20). The proposal in (19) is just a reformulation in dialogical terms of Jacobs' 1984 definition of free focus (see also Beyssade et al. 2004). In terms of the contrast "new vs. old" relativized to the working of the assertion, only the NPA placement is sensitive to the newness of the content.

We are now in a position to account for the distribution of the patterns we observe in the corpus including the answers that at first blush do not abide by our hypothese (13: The XP resolving a narrow question may be marked by NPA placement or by IR.).

\subsection{Analysis of Answers to a Wh-Question}

Assuming (19) and (20), the analysis of patterns (10) can be made explicit for answers to a wh-question:

- Pattern (10a: The Object hosts the NPA on its right edge and an IR on its left) conjoins both the semantic and pragmatic markings.

- Pattern (10b: The Object hosts the NPA on its right edge without an IR) only marks the pragmatic update.

Accordingly, the intonation of answers in pattern (10a) and (10b) fits the working of the question-answer pair: they are intonationally congruent.

- Pattern (10c: The Object shows an IR, while the NPA occurs at the end of the utterance) disjoins the statuses: the semantic relation is marked while the whole content is presented as making up the update of the answer.

Accordingly, the intonation of answers in pattern (10c) is partly noncongruent. 
Finally, $16.9 \%$ of the answers that we left aside in Sect. 3 feature pattern (11): No IR and the NPA occurs at the end of the sentence. As such, the intonation does not cue the semantic relation holding with the question and they sound like All Focus answers. They make up a clear case of intonational noncongruence. This is probably why there are so few of these patterns in the corpus.

\subsection{Analysis of Answers to a Broad Question}

At first blush, the analysis of answers to a broad question should be simpler, since only the placement of NPA is relevant: we expect NPA at the end of the sentence, which corresponds to pattern (11: NPA occurs at the right edge of the utterance). And indeed, $69.2 \%$ of the answers in the corpus show pattern (11).

We left aside $30.8 \%$ of the answers in Sect. 3. They show NPA at the right edge of the Object, which indeed corresponds to patterns (10a) or (10b), which we observed for answers to a wh-question. In other words, those answers are intonationally realized as answers to a wh-question. As such, they make up a case of intonational noncongruence. Their number in the corpus is relatively high. We may speculate that is in line with a tendency observed in naturally occurring contexts: speakers tend to offer answers which are more informative than those that are required by polar or broad questions. Such a speculation will have to be consolidated by experimental evidence.

\subsection{Reanalysis of IR}

Now, we observe that $19.2 \%$ of the answers to a broad question show a highlighted Object while the NPA is at the right edge of the sentence, which corresponds to pattern (10c). According to (20), we should analyze them as resolving a question. Assuming a hierarchical model of dialogue à la Büring (2003) or Roberts (1996), we could posit a covert intermediary question as we did in the informal analysis of (16). But, this is not necessarily the intuition triggered by those answers. One of the more received views on initial rise is that of a marker of empathy as it can be found in exclamations or emphatic expressions more generally ("C'est MERveilleux!" This is wonderful! "Je le Deteste!" I hate him!) (Féry 2001; Grammont 1933). Correspondingly, the intuition is that IR in those answers may have an expressive flavor: a marker of empathy with an element of the content (21a) (Kuno 2004). It may also be used as a centering marker for the discourse topic to come (19c).

(21) Qu'est-ce qu'il s'est passé?

a. Martine a abimé la valise à la GARE.

a. Martine has damaged the suitcase at the train station.

b. Je lui avais recommandé de prendre un sac à dos.

b. I had told her to take a backpack.

c. C'était ma valise préférée.

c. It was my favorite suitcase. 
If this intuition is correct, we would have to generalize (20) into (22):

(22) IR sets off a constituent that is salient at the semantic or pragmatic level.

Claim (22) means that IR is functionally underspecified. Its specific function, probably some sort of semantic or pragmatic distinction needs to be specified by the context. Resolving a question would be one among other prominent statuses of phrases. These hypotheses are for the moment primarily based on our intuitions and clearly need to be further tested by corpus studies and experiments. However, Beyssade et al. 2008 observed that IR is also used to cue the associate of the restrictive adverb seulement ("only"). However, the results of Experiment III prevent an analysis of IR as a marker of Contrast (i.e., membership in an activated set of alternatives): IR is most probably compatible with Contrast, but not a Contrast marker. According to (22), its use with associative adverbs would precisely be to set off the phrase that plays the role of associate.

\section{Conclusion}

We have identified three sources of variations in the marking of Informational Focus in French. Firstly, there are two strategies to mark the IF of an utterance: initial rises (for narrow IF) and NPA placement (for both narrow and broad IF). Secondly, each strategy has its own phonotactic and pragmatic constraints (that are independent from Focus marking): they account for most of the surface variations. Thirdly, the partition of utterance content into Ground and Focus is not deterministically fixed by the context: it crucially depends on the choice of the Speaker. This is particular true when discourse participants answer questions. In the last part of the paper, we have proposed that IRs and NPA placement are not specialized for the marking of IF. In short, they are not focus markers.

Placement of NPA in the utterance (most often correlated with deaccentuation of XPs to the right) and IRs are two ways of setting off a phrase in French. Both are used in answers, but with different roles. NPA placement marks the part of content that is specifically asserted, which counts for the new content with respect to the working of the assertion. In that respect, placement of NPA is the primary way of marking what is new in answers, and more generally in assertions. On the other hand, IR sets off a phrase for a variety of semantic or pragmatic reasons. It may be used to mark a phrase that resolves the question, thus cueing the semantic relation between questions and answers, but also a phrase endowed with other discourse roles, in particular with respect to the generation of the discourse topic. 


\section{References}

Astésano, C. (2001). Rythme et Accentuation en Français: Invariance et Variabilité Stylistique. Collection Langue et Parole, Recherches en Sciences du Langage, dirigée par Henry Boyer, Editions L'Harmattan, Paris, $337 \mathrm{p}$.

Berg, R., Gussenhoven, van den, C., \& Rietveld, A. (1992). Downstep in Dutch: Implications for a model. In G. J. Docherty \& D. R. Ladd (eds.), Papers in laboratory phonology II: Gesture, segment, prosody (pp. 335-359). Cambridge: Cambridge University Press.

Beyssade, C., \& Marandin, J.-M. (2007). French intonation and attitude attribution. In P. Denis, E. McCready, A. Palmer, \& B. Reese (eds.), Proceedings of the 2004 Texas Linguistics Society Conference: Issues at the Semantics-Pragmatics Interface.

Beyssade, C., Delais-Roussarie, E., Doetjes, J., Marandin, J.-M., \& Rialland, A. (2004). Prosody and Information in French. In F. Corblin \& H. de Swart (eds.), Handbook of French semantics (pp. 477-499). Stanford: CSLI.

Beyssade, C., Hemforth, B., Marandin, J.-M., \& Portes, C. (2008). The prosody of restrictive seulement in French. Third TIE Conference on Tone and Intonation. Barcelone (pp. 15-17), September 2008.

Beyssade, C., Hemforth, B., Marandin, J.-M., \& Portes, C. (2009). Prosodic Markings of Information Focus in French. Interface Discours \& Prosodie Paris, 9-11 Septembre 2009.

Büring, D. (2003). On D-trees, beans, and B-accents. Linguistics \& Philosophy, 26(5), 511-545.

Chafe, W. (1974). Language and consciousness. Language, 50(1), 111-133.

Clifton, C., \& Frazier, L. (2012). Discourse integration guided by the 'question under discussion'. Cognitive Psychology, 65(2), 352-379.

Colonna, S., Schimke, S., \& Hemforth, B. (2012). Information structure effects on anaphora resolution in German and French: A cross-linguistic study of pronoun resolution. Linguistics, 50, 991-1013.

Colonna, S., Schimke, S., \& Hemforth, B. (2014). Information structure and pronoun resolution in German and French: Evidence from the visual-world paradigm. In B. Hemforth, B. Schmiedtova, \& C. Fabricius-Hansen (eds.), Psycholinguistic approaches to meaning and understanding across languages (pp. 175-195). Series in Theoretical Psycholinguistics. Heidelberg: Springer.

Dahan, D., Tanenhaus, M. K., \& Chambers, C. G. (2002). Accent and reference resolution in spoken-language comprehension. Journal of Memory and Language, 47, 292-314.

De la Fuente, I., \& Hemforth, B. (2013). Effects of clefting and left dislocation on subject and object pronoun resolution in Spanish. In J. Cabrelli Amaro, G. Lord, A. de Prada Pérez, \& J. Elana Aaron (eds.), Selected Proceedings of the 16th Hispanic Linguistics Symposium. Cascadilla Proceedings Project, Somerville, MA, USA, pp. 27-45.

Di Cristo, A. (1999). Le cadre accentuel du français contemporain. Langues, 3(2), 184-205; Langues, 4(2), 258-267.

Di Cristo, A., \& Jankowski, L. (1999). Prosodic organisation and phrasing after focus in French. Proceedings of XIVth ICPhS. San Francisco: USA, pp. 1565-1568.

Dohen, M., \& Loevenbruck, H. (2004). Pre-focal Rephrasing, Focal Enhancement and Post- focal Deaccentuation in French. Proceedings of the 8th International Conference on Spoken Language Processing (ICSLP), pp. 1313-1316, http://www.isca-speech.org/archive/interspeech 24 .

Drenhaus, H., Zimmermann, M., \& Vasishth, S. (2011). Exhaustiveness effects in clefts are not truth-functional. Journal of Neurolinguistics, $1 / 2,11$.

Féry, C. (2001). Focus and phrasing in French. In C. Féry \& W. Sternefeld (eds.), Audiatur Vox Sapientiae. A Festschrift for Arnim von Stechow (pp. 153-181). Berlin: Akademie-Verlag.

Féry, C. (2014). Final compression in French as a phrasal phenomenon. In S. Katz Bourns \& L. L. Myer (eds.), Perspectives on linguistic structure and context (pp. 133-156). Amsterdam: Benjamins.

Fonagy, I., Fonagy, Y., \& Sap, J. (1979). A la recherche de traits pertinents prosodiques du français parisien. Phonetica, 36, 1-20. 
German, J., \& D'Imperio, M. (2010). Focus, phrase length, and the distribution of phrase-initial rises in French. Proceedings of 5th International Conference on Speech Prosody (2010; May 11-14: Chicago, USA), 1-4.

Ginzburg, J. (1995a). Resolving questions, I. Linguistics and Philosophy, 18(5), 459-527.

Ginzburg, J. (1995b). Resolving questions, II. Linguistics and Philosophy, 18(6), 567-609.

Grammont, M. (1933). Traité de phonétique. Paris: Librairie Delagrave.

Jacobs, J. (1984). Funktionale Satzperspektive und Illokutionsemantik. Linguistische Berichte, 91, 25-58.

Jun, S.-A., \& Fougeron, C. (2000). A phonological model of French intonation. In A. Botinis (ed.), Intonation: Analysis, modeling and technology (pp. 209-242). Dordrecht: Kluwer.

Jun, S.-A., \& Fougeron, C. (2002). Realizations of accentual phrase in French intonation. Probus, $14,147-172$.

Kadmon, N. (2001). Formal pragmatics: Semantics, pragmatics, presupposition, and focus. Malden/Oxford: Blackwell.

Klein, W., \& Stutterheim, C. von. (2002). Quaestio and L-perspectivation. In C. F. Graumann \& W. Kallmeyer (eds.), Perspective and perspectivation in discourse (pp. 59-88). Amsterdam: John Benjamins.

Krifka, M. (2001). For a structured meaning account of questions and answers. In C. Fery \& W. Sternefeld (eds.), Audiatur Vox Sapientia. A Festschrift for Arnim von Stechow (pp. 287-319). Berlin: Akademie Verlag.

Kuno, S. (2004). Empathy and direct discourse perspective. In L. Horn \& G. Ward (eds.), The handbook of pragmatics (pp. 315-343). Blackwell.

Ladd, R. D. (2008). Intonational Phonology, 2nd edition. Cambridge: Cambridge University Press.

Lambrecht, K. (1994). Information structure and sentence form: Topic, focus and the mental representations of discourse referents. Cambridge: Cambridge University Press.

Michelas, A., \& D'Imperio, M. (2012). When syntax meets prosody: Tonal and duration variability in French accentual phrases. Journal of Phonetics, 4(6), 816-829.

Portes, C., \& Beyssade, C. (to appear). Is intonational meaning compositional? Verbum.

Post, B. (2000). Tonal and phrasal structures in French intonation. Holland Academic Graphics.

Repp, S., \& Drenhaus, H. (2015). Intonation influences processing and recall of sentences by indicating information-structural status of referents as topic vs. focus. Language, cognition and neuroscience. formerly: Language and cognitive processes 30(3), 324-346.

Roberts, C. (1996). Information structure in discourse: Towards an integrated formal theory of pragmatics. In J. H. Yoon \& A. Kathol (eds.), OSU Working Papers in Linguistics, Volume 49. The Ohio State University Department of Linguistics. Reprinted in the 1998 version in Semantics and Pragmatics, Volume 5, 2012, http://dx.doi.org/10.3765/sp.5.6.

Rossi, M. (1999). L'intonation: le système du français. Paris: Ophrys.

Selkirk, L. (2009). A New Paradigm for Studying the Prosodic Distinction between Contrastive Focus and Discourse-New. Presentation at IDP 9. this volume.

Vallduví, E., \& Engdahl, E. (1996). The linguistic realization of information packaging. Linguistics, 34(3), 459-519.

Zimmermann, M., \& Onea, E. (2011). Focus marking and focus interpretation. Lingua, 1/2011; $121(11), 1651-1670$. 